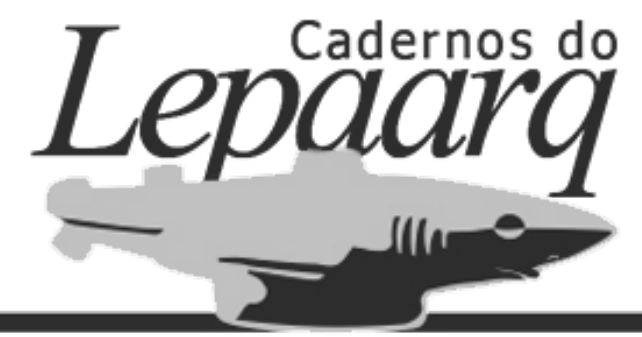

\title{
A NAÇÃO EM UMA XICRINHA DE CAFÉ: REFLEXÕES SOBRE UMA EXPERIÊNCIA NACIONALISTA NO BRASIL NOVECENTISTA (1901-1950)
}

THE NATION IN THE CUP OF COFFEE: REFLECTIONS ON NATIONALISM IN BRAZIL IN THE TWENTIETH CENTURY

Daniel Minossi Nunes

\section{Como citar este artigo:}

NUNES, Daniel Minossi. A nação em uma xicrinha de café: reflexões sobre uma experiência nacionalista no Brasil novecentista (1901-1950). In: Cadernos do Lepaarq, v. XV, n.30., p. 69-79, Jul-Dez. 2018. 


\title{
A nação em uma xicrinha de café: reflexões sobre uma experiência nacionalista no Brasil novecentista (1901-1950)
}

\author{
Daniel Minossi Nunes*
}

Resumo: Foi a partir das pequenas xícaras para café exumadas do sítio arqueológico Praça Brigadeiro Sampaio (RS.JA10), em Porto Alegre/RS, que essa narrativa tomou corpo. Essas xicrinhas funcionaram como uma espécie de gatilho ou, melhor dizendo, como elemento desafiador, estimulante, provocador. A pesquisa histórica acerca desses objetos, produzidos na primeira metade do século XX, colocou-me em contato com o rico universo do comércio internacional do café brasileiro. Divididos entre o Brasil e a Europa, alguns brasileiros preocupados com o consumo do café nacional no exterior expressavam, para além dos interesses calculistas do mercado, certo sentimento de estranhamento com relação à maneira como alguns povos europeus consumiam o café. Motivados por esse estranhamento, os atores escancaram e demarcam as diferenças entre os brasileiros e os europeus, reforçando, a partir do modo de preparo e consumo do café, a ideia de identidade nacional brasileira.

\section{Palavras Chave:}

Nacionalismo; Café; Século XX; Arqueologia Histórica.

\begin{abstract}
From the small coffee cups excavated from the archaeological site Praça Brigadeiro Sampaio (RS.JA-10), in Porto Alegre / RS, that this narrative was created. These cups have acted as a kind of trigger or, rather, as challenging element, stimulating. Historical research on these objects, produced in the first half of the twentieth century, put me in touch with the universe of international trade in Brazilian coffee. Divided between Brazil and Europe, some Brazilians worried about the consumption of national coffee abroad, beyond the calculating interests of the market, expressed a certain feeling of estrangement from the way some European peoples consumed coffee. Motivated by this estrangement, the actors opened up and demarcated the differences between Brazilians and Europeans, reinforcing, from the coffee preparation and consumption, the idea of national identity.
\end{abstract}

\section{Keywords:}

Nationalism; Coffee; 20th century; Historical Archaeology.

*Doutorando em História na Pontifícia Universidade Católica do Rio Grande do Sul (PUCRS), Brasil. E-mail: daniel_minossi@hotmail.com 


\section{INTRODUÇÃOO}

Escrever sobre o nacionalismo é como se embrenhar em um terreno habitado por uma densa vegetação espinhosa. $\mathrm{O}$ assunto, apesar de controverso e polêmico, fascina por suscitar ares mágicos ou, dito de outra forma, pensamentos que, às vezes, apresentam-se incompatíveis com o duro crivo científico-racionalista (JUNCO, 2005). Nesse sentido, é importante assumir que a elaboração de um conceito científico-racionalista e universal de nacionalismo seja algo inviável (SETON-WATSON, 1977, p. 5 apud ANDERSON, 2008, p. 29). Isso não significa, de modo algum, que este fenômeno social seja irrelevante por ser fruto de delírios coletivos. Embora possamos argumentar sobre "a pobreza e a incoerência filosófica" dos nacionalismos (ANDERSON, 2008, p. 31), este raciocínio não ultrapassa a simples constatação e pouco explica sobre o fenômeno em si.

Sendo assim, pensar as nações e os nacionalismos como "produtos culturais" (ANDERSON, 2008) cria uma atmosfera revigorada, um espaço de observação privilegiado, já que insere tais fenômenos no mesmo plano de outras manifestações culturais. Dito isso, cabe levantarmos outra questão: quais são as manifestações culturais que não resultam da criatividade e da invenção? Se "a criatividade e a invenção emergem como as qualidades salientes da cultura [...]" (WAGNER, 2012, p. 68), por que razão cogitar que os nacionalismos devem estar livres das convenções, das arbitrariedades e das incoerências? A nação é produto da criatividade humana, da criatividade dos atores sociais envolvidos nesse megaprojeto moderno. Assim sendo, debruçar-se sobre o nacionalismo requer sensibilidade para perceber a complexidade de elementos envolvidos nesse processo coletivo e, principalmente, exige parcimônia no ímpeto de denunciar a incoerência, a irracionalidade ou a arbitrariedade dos atores.

Subjaz à ideia de nação, em sua concepção moderna, a noção de grupos humanos particulares que diferem entre si (BERLIN, 2002, p. 594). É evidente que não há convergência ou consenso sobre o teor desses gigantescos agrupamentos humanos que denominamos nação. Existe, na realidade, uma profusão de pensamentos sobre a criação e a manutenção destes agregados sociais, que oscilam entre as visões essencialistas, voluntaristas e, também, as que destacam a relevância dos estados multinacionais (ACTON, 2000). Apesar dos desacordos, as nações modernas surgem da aparição e dos repetidos esforços das doutrinas nacionalistas (KEDOURIE, 1988, p. 1). Estas doutrinas, longe de serem receitas fixas e aplicáveis a qualquer contexto espaço-temporal, são formações discursivas, multidimensionais e mutáveis que articulam e mobilizam diferentes elementos com o propósito de fundar e/ou manter uma pretensa unidade nacional (CALHOUN, 2007, p. 45).

É necessário, contudo, que se explore quais são os elementos que, ao fim e ao cabo, são arregimentados (e quem arregimenta) na construção e na manutenção de determinados discursos e práticas que alimentam o sentimento nacionalista. O presente texto se propõe a apresentar, na esteira do comércio internacional do café brasileiro na primeira metade do século $\mathrm{XX}$, o estranhamento dos brasileiros frente ao modo como a população de alguns países europeus preparavam e consumiam o café e, consequentemente, como este sentimento eriçou discursos nacionalistas que embalaram as pretensões brasileiras em educar os paladares europeus.

\section{A NAÇÃO NA PERSPECTIVA DE QUEM?}

A partir de agora, eu gostaria de pôr em destaque os atores sociais que, neste texto, pronunciaram-se em nome da nação brasileira na primeira metade do século XX. Pois, conforme as exortações de Junco (2005, p. 72), o analista deve preocupar-se em identificar quais os grupos se arvoram em falar em nome desse ente metafísico chamado nação. Acho oportuno iniciar esta tarefa a partir da breve apresentação das minhas principais fontes de pesquisa e sobre como estas pessoas e grupos 
foram paulatinamente se manifestando.

O trajeto inicia com a escavação do sítio arqueológico Praça Brigadeiro Sampaio (RS.JA-10), localizado no Centro Histórico de Porto Alegre. Esta campanha arqueológica, realizada entre os anos de 2010 e 2011, evidenciou uma deposição de lixo do século XX, que oscila entre 10cm e 40 cm de profundidade (OLIVEIRA, 2012, p. 95). Desta camada arqueológica, formada entre os anos de 1930 e meados da década de 1940 (OLIVEIRA, 2012; NUNES, 2014), foram identificadas 400 peças de louça de mesa relacionadas aos cafés, restaurantes e bares porto-alegrenses. Deste montante, observou-se que as xicrinhas para café preponderavam, representando $21,5 \%$ (86 peças) de toda a louçaria comercial analisada (NUNES, 2014). O surpreendente número de xicrinhas denuncia um hábito bastante propalado por estas plagas, ou seja, o consumo do café. Diante da altíssima quantidade de xicrinhas, saí em busca de fontes escritas que me ajudassem a compreender o que o registro arqueológico me apontava de modo veemente.

A busca por xicrinhas de café me colocou em contato com riquíssimos textos. A leitura arqueológica da documentação escrita foi muito importante, pois possibilitou que eu percebesse as xícaras em contextos específicos, ampliando o dado arqueológico e auxiliando na sua interpretação (BEAUDRY, 1996). Desse modo, saliento que a pesquisa apostou na complementaridade entre as fontes arqueológicas e escritas (LITTLE, 2006, p. 402). Para fins deste texto, apontarei alguns relatos escritos que ajudaram a iluminar a questão das xicrinhas e, sobretudo, trazer à tona uma discussão preocupada sobre o consumo do café brasileiro na Europa durante a primeira metade do século XX. Meu intento é demonstrar que esta preocupação extrapola os interesses frios e calculistas do capitalismo cafeeiro e assume forte discurso nacionalista. Como veremos, os indivíduos justificam a exportação do café brasileiro e a consequente ampliação dos mercados consumidores europeus a partir de uma linguagem cívico-econômica, patriótica e nacionalista.

Do ponto de vista cronológico, a documentação escrita varia entre 1905 e 1954. São quatro relatórios (anos 1905, 1910, 1926 e 1928), duas atas (anos 1936 e 1954) e, por fim, um artigo de revista (ano 1934). O primeiro relatório, escrito em 1905, está relacionado ao Vice-Consulado em Bremen (Alemanha), onde o relator levanta números sobre as relações comerciais estabelecidas entre os portos brasileiros e o porto de Bremen. Datado de 1910, o segundo relatório se refere às considerações da Comissão da Exposição de Turim-Roma e Propaganda do Café, encaminhadas ao Ministro da Agricultura, Indústria e Comércio. Este relatório, assinado por Antonio de Padua Assis Rezende, apresenta, entre outras coisas, descrições sobre o consumo do café em diversas cidades italianas, tais como Gênova, Pádua, Vicenza, Treviso, Bolonha e Milão. O terceiro relatório, subscrito por Hannibal Porto, em 1926, está relacionado ao Conselho Superior do Comércio e Indústria, onde há uma série de pareceres sobre indesejáveis misturas e falsificações do café na Europa. O quarto e último relatório, datado de 1928, traz algumas considerações do adido comercial do Rio Grande do Sul instalado junto às embaixadas e legações do Brasil na Europa.

Entre os documentos classificados como ata, destaco a ata da sessão do Conselho Federal de Comércio Exterior, reunido em 1936 no Palácio do Itamaraty; e, também, a ata da Assembleia Legislativa do Estado de São Paulo, datada de 1954, que traz o relato do deputado Athié Jorge Coury. Nesta sessão, o referido deputado (que também era corretor oficial de café), além de fazer considerações pessoais sobre o consumo do café no exterior, leu um texto elaborado por Homero Leonel Vieira, cafeicultor e negociante de café que visitou 16 países europeus observando os hábitos relacionados ao consumo do café. Para finalizar, ressalto o artigo intitulado "Factos e Cousas do Café", escrito pelo Dr. Carlos Pinheiro da Fonseca, do Departamento Nacional do Café. Este texto, transcrito da Revista do Departamento Nacional do Café, foi publicado no Diário Oficial da União, em setembro de 1934. O autor do texto faz um grande apanhado que contempla alguns aspectos históricos da cultura cafeeira, aponta os maiores produtores mundiais da rubiácea, os maiores consumidores do café brasileiro no estrangeiro, as- 
pectos botânicos e fitossanitários do café, dados sobre a colheita, classificação, preparo e propriedades da bebida.

Embora as fontes escritas tenham as suas peculiaridades e tenham sido produzidas a fim de cumprir propósitos específicos, é sobre o que elas têm em comum que eu pretendo me deter. Não há dúvida que, em maior ou menor grau, todas as fontes escritas tratam do consumo do café na Europa e retratam, grosso modo, a visão dos funcionários de embaixadas e consulados do Brasil no exterior, dos integrantes de comissões de propaganda do café brasileiro que atuam no estrangeiro, dos corretores oficiais de café, dos grandes cafeicultores e negociantes que possuem estreito contato com os mercados consumidores europeus. Nota-se, assim, que estes indivíduos compartilham um lugar de fala bastante similar. Estes sujeitos, por força de seus respectivos interesses e atividades profissionais, formavam um grupo que habitava uma zona de fronteira. Em certo sentido, os funcionários das embaixadas e consulados brasileiros na Europa, os integrantes das comissões internacionais de propaganda do café, bem como os grandes cafeicultores e negociantes de café que atuavam no exterior, por exemplo, aparentavam-se aos exilados, refugiados e migrantes (ACTON, 2000, p. 34; BHABHA, 1998, p. 198). Divididos entre o Brasil e a Europa, estes "homens do café" eram figuras híbridas que experimentaram "esse processo estranho da duplicação, divisão e intercâmbio do eu" (BHABHA, 1998, p. 204). A condição de limiaridade do grupo propiciou falas mui significativas, principalmente porque elas demonstravam o estranhamento com o modo como muitos europeus consumiam o café na primeira metade do século XX. Contudo, estas narrativas não são sem intenção, pois, em último caso, elas estavam demarcando limites e diferenças que contrapunham o consumo do café entre brasileiros e europeus.

\section{O QUE OS BRASILEIROS FALAVAM?}

Sob a ótica moderna, a nação é um corpo indiviso e homogêneo (HUTCHINSON, 2000). Contudo, alguns autores contemporâneos (BHABHA, 1998; HUTCHINSON, 2000; CHATTERJEE, 2008) desafiaram o raciocínio moderno - a nação como sociedade unitária - e argumentaram em favor da nação heterogênea, fissurada, composta por diversos grupos e interesses, isto é, a nação como arena política. Este texto, que procura alinhar-se à perspectiva da nação heterogênea, de modo algum sustenta que as narrativas proferidas pelo grupo cafeicultor em questão representaram o único discurso possível sobre a nação brasileira na primeira metade do século XX. Como assevera John Hutchinson (2000, p. 654), não existe formação e manutenção da nação sem conflitos ou contradições. A noção de nação do grupo cafeicultor pode rivalizar com outras concepções ou projetos nacionais, provocando divergências políticas e/ou culturais no seio da nação. Mas, afinal, em que medida o comércio internacional e a propaganda do café participaram do difuso processo de construção da nação brasileira? Precisamos, inequivocamente, escutar os atores sociais envolvidos.

Não é novidade que o Brasil, durante a primeira metade do século XX, ocupava uma posição hegemônica na produção e comércio internacional do café. A rubiácea que era a "[...] pedra angular de nosso edifício econômico e o nosso grande artigo de exportação, tanto para a Europa como para a América” (DIARIO OFFICIAL, 1928, p. 7956), acabou propiciando a concentração de muita riqueza e poder nas mãos dos cafeicultores. O cultivo do café alçou o Brasil a uma invejável condição de maior produtor mundial do produto e, a partir dessa conjuntura, passou a alimentar um desejo eufórico e autodeclarado de se tornar o instrutor ou catequizador dos mercados consumidores internacionais. O Brasil, em outras palavras, estaria em condições de ensinar os países europeus a consumir o verdadeiro e perfeito café. Saliento, assim, que não se tratava de um nacionalismo meramente econômico, mas, como escreveu Calhoun (2007, p. 29), um nacionalismo "motivado sólo parcialmente por cuestiones económicas". Existia uma mistura entre desejos econômicos (vontade de vultuosos lucros) e orgulho nacional. Como veremos, este sentimento fica evidente na declaração do adido comercial do Rio Grande do Sul, em 1928: 
Os exportadores brasileiros podem se deixar seduzir pela idéa de que a absorvencia de cafés brasileiros, sob rubricas de outras procedências estrangeiras, facilita o escoamento do producto, e quantas vezes já ouvi dizer: "Que importa que se venda o café do Brasil sob outras denominações de proveniencia, comtanto que se venda muito café; sendo nós os maiores productores, fatalmente o nosso será consumido". Esse conceito é erroneo. Não é deixando o renome do café brasileiro desmoralizar-se no estrangeiro que augmentaremos as nossas vendas. É precizamente porque os cafés brasileiros são vendidos sob denominações que não são as verdadeiras que teremos cada vez mais difficuldades em tornar conhecidas, pela verdadeira origem, as qualidades superiores das nossas melhores regiões cafeeiras (DIARIO OFFICIAL, 1928, p. 7957).

Ao adido é incômoda a ideia de que o comércio internacional do café brasileiro esteja desassociado de sua origem. Não é suficiente que o país siga ocupando a posição de maior produtor mundial e, com isso, esteja movimentando cifras estratosféricas. É necessário que grãos e goles de café carreguem consigo as insígnias da nação brasileira. O comércio extensivo não deve ser unicamente perseguido porque gera riqueza e poder, mas, também, porque se trata do nosso café, produzido nas nossas fazendas, em nosso país (BERLIN, 2002, p. 595). Sendo assim, o café (planta, grão, bebida) passa a despertar paixões nacionalistas, a ponto de Athie Coury, corretor oficial do café e deputado estadual de São Paulo, declarar que estava "tão afeiçoado à nossa rubiácea quanto [estima] São Paulo e o Brasil” (DIARIO OFICIAL DO ESTADO DE SÃO PAULO, 1954, p. 60).

O café, na esteira do êxito comercial, converte-se em objeto dotado de uma aura nacional. Ao encontro disso, Homero Leonel Vieira, técnico cafeicultor e grande comerciante na praça de Santos, afirma que

[...] havia algo desolador para nós brasileiros: era constatarmos que, raramente, tanto na Alemanha, França ou Itália, via-se um cartaz sôbre as amostras anunciando "Café Santos" ou mesmo "Café do Brasil". Quase nunca encontravamos, e quando algum havia, estava sempre em posição secundária na vitrine, como querendo esconderse, envergonhado, talvez pelo descaso com que vêm sendo oferecidas na Europa, amostras do nosso produto. Os pequenos "placards" anunciavam constantemente cafés da Colômbia, México, Haiti, outros países da América Central e colônias da África; mas muito raramente do Brasil. E isto era regra em tôda a Europa (DIARIO OFICIAL DO ESTADO DE SÃO PAULO, 1954, p. 60).

A luta do grupo cafeicultor que atuava com a intenção de assegurar o consumo crescente do café brasileiro no exterior era, também, uma busca insistente de "que se não desnacionaliz[asse] o café do Brasil” (DIARIO OFFICIAL, 1928, p. 7959). Este esforço suscitou uma série de observações, reflexões e estranhamentos sobre o modo como o café era consumido em determinados países e localidades europeus. Era apontado, com certa frequência, o quanto alguns países, localidades ou determinados grupos sociais eram resistentes ao consumo do café. Segundo um relatório emitido em 1905 pelo Vice-Consulado em Bremen, as classes abastadas da referida cidade consumiam pouco café, pois preferiam o chá ou o chocolate (DIARIO OFFICIAL, 1905, p. 6576). Em 1928, o adido comercial do Rio Grande do Sul elucubrava sobre a resistência inglesa ao café, pois, segundo ele, “[...] os mercados inglezes mostram-se rebeldes ao nosso produto. Além da predilecção popular pelo chá, o gosto dos consumidores de café na Grã-Bretanha pende para os cafés suaves da América Central, da Colombia, das Indias Inglezas e das Antilhas" (DIARIO OFFICIAL, 1928, p. 7957).

Outra querela muito comum nos textos consultados é sobre o habitual uso dos sucedâneos do café na Europa. Ao paladar brasileiro, era detestável o hábito de alguns europeus em misturar substâncias estranhas ao café. As denúncias a esse tipo de prática eram muito comuns, especialmente contra os

[...] defraudadores que dão o nome de café a misturas em que entram varias substancias, salvo o café: amendoim, grão de bico, cevada, milho, figos e muitas outras substancias que submettidas á torrefacção, convenientemente desodorizadas e depois aromatizadas com o cheiro do café, são reduzidas a pó e habilmente comprimidas em moldes e fôrmas que lhe dão exactamente o aspecto do verdadeiro grão á primeira impressão visual (DIARIO OFFICIAL, 1928, p. 7958). 
Para o grupo cafeicultor brasileiro, era um verdadeiro sacrilégio o consumo de uma bebida denominada café que, na verdade, era resultado de misturas de outros produtos, como a chicória, o amendoim, a cevada, etc. Os sucedâneos do café eram alvo de críticas e denúncias assíduas dos cafeicultores brasileiros atuantes no exterior. A ideia, segundo eles, era conter as adulterações, as fraudes e as falsificações que impediam os europeus de consumir uma bebida de qualidade superior e de excelência. Em 1926, inclusive, foi sugerido ao Ministério das Relações Exteriores que orientasse os representantes diplomáticos na Europa a "uma vigilante assistencia ao consumo do café, afim de conhecer da existencia e da extensão das fraudes em uso" (DIARIO OFFICIAL, 1926, p. 5451). E, além disso, que fosse "provocado um entendimento com o governo italiano, no sentido de ser fiscalizado, severamente e pela melhor fórma o commercio e o consumo do café na Italia, de modo a evitar as fraudes [...]" (DIARIO OFFICIAL, 1926, p. 5451).

O que os cafeicultores brasileiros pareciam fazer questão de ignorar é que o consumo dos sucedâneos do café em algumas partes da Europa era bastante comum. Ou seja, havia, sim, uma preferência por este tipo de produto, em detrimento do café. Conforme o relator Hannibal Porto, “em Bruxellas tive occasião de verificar no anno passado, que o consumidor exige systematicamente, ao comprar o café, que lhe seja vendida igual quantidade de chicorea, cuja venda e uso, como se sabe, são permittidos naquelles paizes [França e Bélgica], até 75 para 100 de café puro" (DIARIO OFFICIAL, 1926, p. 5450).

A lista de estranhamentos sobre os hábitos europeus supera a questão dos sucedâneos do café ou, ainda, a questão da resistência de certos grupos sociais (classes abastadas bremenses) ou povos (ingleses) em consumir o café. Os brasileiros julgavam inteiramente inconveniente as instalações comerciais onde o café era servido, criticavam as torrefações, o preparo da bebida e, por fim, a xícara onde o café era consumido. Apesar de algumas exceções, nota-se, a partir da leitura do relatório expedido pela Comissão da Exposição de Turim-Roma e Propaganda do Café, que em Gênova, Vicenza e em Treviso os bares e torrefações eram "rudimentares e imperfeitos", "montados com deficiencia" e "mal montados" (DIARIO OFFICIAL, 1910, p. 7670-7671).

Com relação ao preparo da bebida, os brasileiros também teciam críticas. Homero Leonel Vieira, em 1954, afirma que, com exceção de estabelecimentos comerciais que utilizavam as modernas máquinas italianas de café expresso, o popular “café de filtro" produzia uma "das piores coisas que bebemos na Europa com o nome de café" (DIARIO OFICIAL DO ESTADO DE SÃO PAULO, 1954, p. 60). De acordo com o técnico cafeicultor e negociante,

\footnotetext{
Generalizadíssimo na França, cremos ser o "café de filtro" o maior inimigo do próprio café naquele país. A infusão produzida não pode, parece-nos, representar o café com todas as suas propriedades, porque, comumente, a água apenas dá um banho no pó, sendo ainda, conforme já dissemos, o seu paladar bastante desagradável para aqueles que conhecem um bom café expresso (DIARIO OFICIAL DO ESTADO DE SÃO PAULO, 1954, p. 60).
}

O recipiente onde os europeus consumiam o café na primeira metade do século XX também foi descrito como impróprio. A xícara, dessa forma, estava sob o olhar desconfiado dos brasileiros. Conforme Homero Leonel Vieira, "na Alemanha, onde, em geral, costumam servi-lo em xícaras que se assemelham às nossas de chá, é, para nós, paulistas, de péssimo paladar” (DIARIO OFICIAL DO ESTADO DE SÃO PAULO, 1954, p. 60). No texto "Factos e Cousas do Café", escrito em 1934 por Carlos Pinheiro da Fonseca, do Departamento Nacional do Café, há outra referência importante sobre as xícaras de café. Ao explicar os procedimentos adequados para obtenção de uma bebida de qualidade, Fonseca esclarece que 
Ha um sem numero de apparelhos para preparar o café. As cafeteiras mais usuaes e as melhores são as de porcellana ou vidro, especialmente preparado, providas de um filtro de sacco de flanella no qual se introduz o café em pó. Dosada devidamente a quantidade de agua, de accordo com a do pó, no gráu de moagem convenientemente (geralmente o chamado granulado), e, evidentemente, o numero de chicaras (a pequena chicara de cafe á brasileira tem 50 a 60 c.c. de capacidade e a quantidade de pó vae de 6 a 12 grs., conforme o gráu de concentração que se quer obter), derrama-se pequena quantidade de agua (antes que entre em ebulição), sobre o pó o café (DIARIO OFFICIAL, 1934, p. 18922).

O curioso da citação acima é a referência feita à xícara para o consumo do café. O autor é muito preciso ao afirmar que a xícara para café que possui entre $50 \mathrm{ml}$ e $60 \mathrm{ml}$ (xícara pequena) é a xícara à brasileira. Se fizermos uma leitura conjunta das citações de Homero Leonel Vieira e de Carlos Pinheiro da Fonseca e associarmos ao grande número de xícaras pequenas para café encontradas no sítio arqueológico Praça Brigadeiro Sampaio (86 xicrinhas), podemos supor que o consumo de café em xícaras pequenas fosse uma peculiaridade, uma preferência, um hábito amplamente difundido nos grandes centros urbanos brasileiros na primeira metade do século XX, algo que não era observado na Alemanha, por exemplo. Além disso, suponho que o consumo de café em xicrinhas tenha sido uma invenção brasileira do início do século XX, nascida da prova de xícara. ${ }^{1}$

\section{O CAFEZINHO PERFEITO: UMA MISSÃO NACIONAL}

Na seção anterior, fiz um breve levantamento de alguns elementos que, segundo a leitura dos cafeicultores brasileiros, entravavam o aumento do consumo do café brasileiro na Europa e que, em certo sentido, poderiam ameaçar a supremacia internacional do Brasil. O europeu, de acordo com a fala dos brasileiros, desconhecia o modo correto de preparar um café de qualidade superior. Da má torrefação às impróprias xícaras empregadas, das péssimas cafeteiras aos sucedâneos, dos bares e cafeterias mal instalados à falta de hábito em consumir o café, o europeu, de modo geral, pecava em todo o procedimento para o preparo e consumo da bebida. Isso, em hipótese alguma, representava um problema insolúvel. O Brasil, ou melhor, os representantes do capitalismo cafeeiro que falavam em nome do Brasil, tinham uma inabalável certeza sobre a sua missão frente aos países europeus. A missão tinha como foco disciplinar os paladares europeus, ensiná-los o modus operandi infalível para o preparo da bebida perfeita. Esse raciocínio fica muito evidente na transcrição a seguir: "Não é, pois, descabido que nós Brasileiros, os maiores produtores e abastecedores dos mercados mundiaes, grandes consumidores e apreciadores de café, estabeleçamos o catecismo de tratamento do precioso cotyledon para que delle se extraia a bebida perfeita com o maximo de suas qualidades sápidas, aromaticas e hygienicas e que lhe apregoemos as propriedades" (DIARIO OFFICIAL, 1928, p. 7959).

A propaganda do café brasileiro no exterior pensava em corrigir o modo como os europeus preparavam e consumiam a bebida. As estratégias adotadas a fim de atingir a educação do paladar eram diversas. Nesse sentido, é interessante o relato do "commissario geral do Brazil na Exposição do Turim-Roma e da propaganda do café e de outros productos nacionaes no estrangeiro". Segundo Antonio de Padua Assis Rezende, que assina o relatório,

A acção desta commissão deverá estender-se, finalmente, à ultima ramificação do caminho percorrido pelo nosso producto e remodelar os processos adoptados que, até, neste ponto, são imperfeitos. Já assignalámos ligeiramente o que nos cumpre fazer quanto ás torrefacções; mas a nossa acção deverá mesmo chegar ás casas onde se vende o nosso producto em liquido, aos hotéis, ás companhias de wagons-lits, ás companhias de vapores, ás casas de família, etc., demonstrando a perfeição de nossas cafeteiras e como se faz economicamente o emprego do pó, percorrendo assim a escala por que passa o café, nas suas várias manipulações, até ser reduzido á excellente bebida (DIARIO OFFICIAL, 1910, p. 7677). 
Nota-se que a cruzada propagandística visava alcançar as residências particulares, empresas, bares, restaurantes e quaisquer outros lugares recônditos onde o café fosse consumido. Do ponto de vista prático, é interessante observar um rápido exemplo de como era executada a aproximação entre os agentes cafeicultores e os consumidores europeus. O comissário Antonio de Padua Assis Rezende explica que

Por verificarmos a possibilidade de estender a nossa propaganda até as pequenas cidades de cada provincia, fizemos um excursão pelo Piemonte. Logo em Bussalia, fazendo experiencias praticas, conseguimos que o Sr. Boccaleri Giuseppe, proprietario do Hotel Appennino, com a mais expressiva satisfação, se encarregasse da venda do nosso pó, das nossas cafeteiras e até de ensinar como se deve preparar o café nas casas de família (DIARIO OFFICIAL, 1910, p. 7670).

É evidente que a estratégia do tête-à-tête estava inserida em um amplo "programma do Governo Brazileiro" que, através de comissões enviadas ao exterior, buscava firmar parcerias com as câmaras de comércio na Europa. Em Treviso, na Itália, o Sr. Isidoro Coletti, grande capitalista e presidente da Camera di Commercio, "[recebeu] com a maior satisfação o programma do nosso Governo, assegurou-nos o seu concurso e está disposto a entrar em accôrdo com a commissão para se encarregar da montagem de torrefacções e cafés modelos" (DIARIO OFFICIAL, 1910, p. 7671). O Brasil, através dos cafeicultores e instituições governamentais interessadas no comércio do café no exterior, estava verdadeiramente empenhado em modelar, disciplinar e ensinar os europeus a preparar e consumir o superior e inigualável café à brasileira.

Em uma economia capitalista, o lucro e a propaganda são vitais. É claro que um dos interesses principais dos cafeicultores brasileiros era atingir índices cada vez mais altos de produção e venda do café no exterior. Contudo, eu gostaria de frisar o quanto essa missão propagandística brasileira, que fomentava o crescimento dos lucros e a educação dos paladares europeus, incorporou um discurso patriótico e nacionalista. Penso que a fala do deputado Athié Jorge Coury, transcrita abaixo, exemplifica o meu argumento.

[...] o ideal seria uma organização para a distribuição do café na Europa, o que iria desde sua venda por atacado, até a venda em xícaras, facilitando toda a espécie de tamanho de negócios de café verde e torrado, competindo-lhe, também, a necessaria e indispensável propaganda. Teria um programa cívico-econômico com o fim primordial de alargar o mercado europeu para os cafés brasileiros e difundir o hábito de sua bebida, norteando um programa eminentemente patriótico e uma ação de alto alcance público (DIARIO OFICIAL DO ESTADO DE SÃO PAULO, 1954, p. 60).

Segundo entendo, a questão do comércio cafeeiro na Europa está sendo pensada por um viés nacionalista. Quando o nobre deputado se refere a um "programa cívico-economico" ou "programa eminentemente patriótico", não resta dúvida de que a motivação para a ampliação dos mercados consumidores externos não se restringe aos interesses meramente econômicos. Revela-se, assim, uma espécie de capitalismo de coração quente, em que o sentimento patriótico opera como um importante elemento propulsor da política econômica expansionista pensada pelos grandes cafeicultores. Caso semelhante foi observado na fala de Hannibal Porto, em 1926. Este, ao referir-se ao empenho do Dr. Laurindo Ribeiro no combate à falsificação do café na Itália, elogia o “[...] compatriota [...] que tão zeloso se mostrou com o seu gesto patriotico perante a Camara de Commercio Italo-Brasileiro de Milão" (DIARIO OFFICIAL, 1926, p. 5451). Percebe-se que ambos os atores não falam somente em nome dos cafeicultores, pelo contrário, eles falam em nome do país, da pátria, da nação. O projeto expansionista, para além dos ganhos econômicos ou financeiros, alimenta-se de um sentimento nacionalista. 


\section{BREVE EPÍLOGO}

Aos brasileiros, com relação ao consumo do café, tudo soava estranho em boa parte da Europa: a torrefação, o preparo da bebida, os sucedâneos e as misturas, as instalações onde a bebida era vendida e as xícaras onde o café era consumido. Este estranhamento escancarava a fronteira cultural entre brasileiros e europeus. Os indivíduos que representavam os interesses do capitalismo cafeeiro brasileiro na Europa, para além das preocupações estritamente financeiras que estas diferenças poderiam acarretar, sentiram-se motivados a reproduzir discursos em nome da nação. O grande sujeito, que tomava corpo a cada fala dos brasileiros, era a nação brasileira. O solo, a fazenda, o fruto do café, a torrefação, a cafeteria, a preparação da bebida e a xícara passaram pelo crivo do discurso nacionalista e foram alçados à categoria de o nosso solo, as nossas fazendas, o nosso fruto do café, a nossa torrefação, as nossas cafeterias, o nosso modo de preparar o café e as nossas xicrinhas para café. A nação, por intermédio destes brasileiros que experimentaram uma zona de fronteira entre Brasil e Europa, foi coletivamente criada, evocada e mobilizada como um ente capaz de educar o paladar europeu para sorver o melhor café do mundo - o café à brasileira.

A retórica nacionalista não está amparada unicamente nas abstrações presentes nas fontes escritas pesquisadas. A nação, enquanto megaprojeto moderno, requer a orquestração de inúmeras formas de agenciamento. Os objetos não foram excluídos desse processo de construção e manutenção da ideia de nação brasileira na primeira metade do século XX. Neste caso, a fim de retomar brevemente o início deste texto, as 86 xicrinhas para café, desenterradas de um sítio arqueológico em Porto Alegre/RS, podem ser interpretadas como partícipes na manutenção de certa brasilidade. O uso de xicrinhas próprias ao consumo do café, em comparação ao observado em diversos países europeus na primeira metade do século XX, aparece como algo tipicamente brasileiro. O difundido e peculiar uso desses objetos em território nacional foi ironicamente ressaltado por brasileiros que viviam na condição de estrangeiros na Europa. Ou seja, os "homens do café" que experimentaram zonas de intersecção entre o "aqui dentro" e o "lá fora" foram capazes de enxergar com invejável lucidez como as xicrinhas para café estavam intimamente relacionadas ao contexto cultural brasileiro e, além disso, como essas xícaras deveriam ser mobilizadas em território europeu a fim de demarcarem o correto e insubstituível jeito brasileiro de consumir o café. Sendo assim, as gigantescas aspirações nacionalistas, que buscam articular enormes agrupamentos humanos, contam com a ação da vida material na sua sutileza e quase imperceptibilidade, desafiando, por fim, os que imaginam que a nação brasileira não caiba em pequenas xícaras para café. 


\section{REFERÊNCIAS}

ACTON, Lord. Nacionalidade. In: BALAKRISHNAN, G. (Org.). Um mapa da questão nacional. Rio de Janeiro: Contraponto, 2000 .

ANDERSON, Benedict. Comunidades imaginadas. São Paulo: Companhia das Letras, 2008.

BEAUDRY, Mary. Reinventing Historical Archaeology. In: CUNZO, Lu Ann De; HERMAN, Bernard. Historical Archaeology and the study of American Culture. Tennessee: Tennessee Press, 1996.

BERLIN, Isaiah. Estudos sobre a humanidade: uma antologia de ensaios. São Paulo: Companhia das Letras, 2002.

BHABHA, Homi. O local da cultura. Belo Horizonte: Editora da UFMG, 1998.

CALHOUN, Craig. Nacionalismo. Buenos Aires: Libros dels Zorzal, 2007.

CHATTERJEE, Partha. La nación em tiempo heterogéneo y outros estudios subalternos. Buenos Aires: Siglo XXI, 2008.

HUTCHINSON, John. Etnicity and modern nations. Ethnic and Racial Studies. Vol. 23, n. 4, p. 651-669, 2000.

JUNCO, José Álvares. El nombre de la cosa: debate sobre el término nación y outros conceptos relacionados. Madrid: Centro de Estudios Políticos y Constitucionales, 2005.

KEDOURIE, Elie. Nacionalismo. Madrid: Centro de Estudios Constitucionales, 1988.

LITTLE, Barbara. Historical Sources. In: BALME, Jane; PATERSON, Alistair. Archaeology in practice: a student guide to archaeological analyses. Oxford: Blackwell Publishing, 2006.

NUNES, Daniel Minossi. Nos bares, cafés e restaurantes de Porto Alegre: cultura material e o ideário moderno em meados do século XX. (Mestrado) Programa de Pós-Graduação em Antropologia, Instituto de Ciências Humanas, Universidade Federal de Pelotas, Pelotas, 2014.

OLIVEIRA, Alberto Tavares Duarte de. Plano de trabalho para monitoramento arqueológico junto à obra de instalação da linha de transmissão subterrânea 230KV, nas praças Júlio Mesquita e Brigadeiro Sampaio - Município de Porto Alegre/RS. Relatório técnico final. Porto Alegre, 2012.

WAGNER, Roy. A invenção da cultura. São Paulo: Cosac Naify, 2012.

\section{FONTES IMPRESSAS}

DIARIO OFFICIAL. Relatório do primeiro trimestre de 1905. Vice-Consulado em Bremen. Ministério das Relações Exteriores. Rio de Janeiro, p. 6576, 19 set. 1905.

DIARIO OFFICIAL. Relatorio geral enviado ao Sr. ministro da Agricultura, Industria e Commercio pelo commissario geral do Brazil na Exposição do Turim-Roma e da propaganda do café e de outros productos nacionaes no estrangeiro. Rio de Janeiro, p. 7669, 23 set. 1910.

DIARIO OFFICIAL. Parecer n. 10. Serviço de Commissões. Conselho Superior de Commercio e Industria. Rio de Janeiro, p. 5450, 09 março 1926.

DIARIO OFFICIAL. Relatorio do addido commercial do Estado do Rio Grande do Sul junto ás Embaixadas e Legações do Brasil na Europa, relativo ao anno de 1926. Rio de Janeiro, p. 7959, 23 mar. 1928.

DIARIO OFFICIAL. Factos e cousas do café. Rio de Janeiro, p. 18918, 14 set. 1934.

DIARIO OFICIAL DO ESTADO DE SÃO PAULO. Assembléia Legislativa do Estado de São Paulo. 132a Sessão Ordinária, da $4^{\text {a }}$ Sessão Legislativa, da $2^{\text {a }}$ Legislatura, realizada em 19 de novembro de 1954. São Paulo, p. 46, 20 nov. 1954.

Recebido em: 11/06/2018 Aprovado em: 23/09/2018 Publicado em: 30/11/2018 